Int. J. Electrochem. Sci., 14 (2019) 8195 - 8205

\title{
On the Origin of Phase Angle in Warburg Finite Length Diffusion Impedance
}

\author{
V.V. Pototskaya ${ }^{1}$, O.I. Gichan ${ }^{2, *}$ \\ ${ }^{1}$ Vernadskii Institute of General \& Inorganic Chemistry, National Academy of Sciences of Ukraine, \\ Palladina Prosp. 32-34, 03142 Kyiv, Ukraine \\ ${ }^{2}$ Chuiko Institute of Surface Chemistry, National Academy of Sciences of Ukraine, Henerala \\ Naumova Str. 17, 03164 Kyiv 164, Ukraine \\ *E-mail: gichan@isc.gov.ua, gichan@meta.ua
}

doi: $10.20964 / 2019.08 .97$

Received: 1 January 2019/ Accepted: 26 February 2019 / Published: 30 June 2019

We develop a simple physical model which describes the origin of phase angle of the Warburg finite length diffusion impedance. We show that diffusion results in a phase delay of the surface concentration of species with respect to current. The phase shift between current and concentration is a function of a ration of the Nernst diffusion layer thickness to an oscillating length. The phase angle of the Warburg finite length diffusion impedance has a maximum that does not depend on either the Nernst diffusion layer thickness values or the diffusion coefficient of species. The peculiarities of the phase angle changes at the transition from the Warburg finite length diffusion impedance to electrode impedance are shown. The effects of the Nernst diffusion layer thickness, charge-transfer resistance, diffusion coefficient, double layer capacitance, and electrolyte resistance on the behavior of phase angle are discussed.

Keywords: Warburg impedance, Phase angle, Mass transfer, Nernst diffusion layer

\section{FULL TEXT}

(C) 2019 The Authors. Published by ESG (www.electrochemsci.org). This article is an open access article distributed under the terms and conditions of the Creative Commons Attribution license (http://creativecommons.org/licenses/by/4.0/). 